\title{
Direct Pressure Alkaline Leaching of Scheelite Ores and Concentrates
}

\author{
Patrícia Leitão ${ }^{1} \cdot$ Aurora Futuro $^{1} \cdot$ Cristina Vila $^{1} \cdot$ Lurdes Dinis $^{1} \cdot$ Anthony Danko $^{1} \cdot$ António Fiúza $^{1}$
}

Received: 27 November 2018 / Accepted: 4 July 2019 / Published online: 19 July 2019

(C) The Author(s) 2019

\begin{abstract}
The average global recovery rates for processing scheelite ores by physical methods are normally in the range 50 to $70 \%$, and it is problematic to attain a minimum grade of $60 \% \mathrm{WO}_{3}$ in the concentrates without penalizing further this yield. Direct hydrometallurgical processing of low-grade concentrates or medium- to high-grade ores may become an interesting global economic alternative as it allows increasing the recovery rate, avoiding major penalizations due to the grade of the concentrate and increasing the added value of the final product. Leaching of scheelite by sodium carbonate presents several advantages such as its selectivity regarding the dissolution of troubling metals like iron and aluminium, allowing for a simple and flexible process diagram. However, it has the disadvantage that it is performed at high temperature and pressure with a high consumption of reagents. The feasibility of leaching is appraised by the extraction yield and selectivity, but also by the operating cost. Considering these aspects, a relevant objective of the research was to transform alkaline pressure leaching into a feasible processing alternative directly applicable to both medium- and high-grade ores and simultaneously to low- and high-grade concentrates produced by physical methods. The research used ore samples and low-grade concentrates from a typical skarn orebody as well as high-grade concentrates from a chalcopyrite-scheelite orebody. Different operating conditions were tested. Temperature, pressure and reagent concentration showed to be fundamental, but not exclusive, in determining the leaching behaviour. The operating conditions are milder than the ones generally proposed in the literature or currently in use in industry, but with higher carbonate consumptions. The research was oriented towards potential industrial implementation allowing for the application of optimization methods and straight scale-up to pilot-plan design and project.
\end{abstract}

Keywords Scheelite $\cdot$ Alkaline pressure leaching $\cdot$ Sodium carbonate

\section{Introduction}

Tungsten is of vital importance to modern society, not only because of its scarcity and strategic importance, leading to its classification as critical by the European Commission since 2011 [1], but also because of its demand being estimated to grow at an annual rate between 4.6 and $6.4 \%$ from 2013 to $2018[2]$.

Highlights - Direct leaching of medium- to high-grade scheelite ores and low-grade concentrates

- Flexible and adjustable processing

- Milder operating conditions

- Co-products or recycling

- Generic flexible process flowsheet easily transposable to industrial conditions

António Fiúza

afiuza@fe.up.pt

1 Cento de Recursos Naturais e Ambiente (CERENA), Faculty of Engineering, University of Porto, Rua Dr. Roberto Frias s/n, 4200-465 Porto, Portugal
Economic tungsten ores fall into two main categories: the wolframite group that includes iron and/or manganese tungstate minerals (ferberite, wolframite and huebnerite) and the scheelite group (calcium tungstate). Scheelite is normally found in contact with skarn minerals with a broad variety of complex compositions or in quartz veins. Considering the mineral associations, these ores can be classified into five categories: simple scheelite, scheelite-sulphides, scheelitecassiterite, scheelite-calcite-apatite, and scheelite-powellite [3].

In many skarn-type scheelite deposits, the mineral liberation occurs at very fine sizes (frequently below $25 \mu \mathrm{m}$ ). The mineral processing is performed both by gravity methods (coarse sizes) and by flotation (finer sizes). Cut-off grades for open-pit extraction are normally in the range 0.05 to $0.08 \% \mathrm{WO}_{3}$, and the average grade of ores is normally from 0.2 to $0.6 \% \mathrm{WO}_{3}$. The minimum commercial grade for concentrates without penalization is $60 \%$ in $\mathrm{WO}_{3}$, and the penalizing impurities are $\mathrm{Cu}, \mathrm{Pb}, \mathrm{Zn}, \mathrm{As}, \mathrm{Bi}, \mathrm{Mo}, \mathrm{Sn}, \mathrm{S}, \mathrm{Sb}, \mathrm{Mn}$ and $\mathrm{Zn}$. Global recovery rates are not very high, normally in the interval from 50 to $70 \%$, depending on the specificities of the ore. 
In the past, scheelite concentrates (grades around 60\%) were processed by acid digestion, mainly with hydrochloric acid, producing tungstic acid that was subsequently dissolved by ammonium hydroxide. This process was replaced by digestion with sodium hydroxide or sodium carbonate.

The main objective of the research was to study the pressure leaching of scheelite ores by sodium carbonate in order to treat directly medium- to high-grade ores by hydrometallurgical processes, thus avoiding the previous phase of ore processing by physical methods that generally have a low recovery. At the same time, it also examines the processing of low- or high-grade concentrates by the same method. Production of low-grade concentrates (range from 12 to $40 \%$ ) may maximize the global recovery rate of scheelite, thus becoming an interesting economic alternative, if these concentrates will be further processed by hydrometallurgical methods producing another final product. In addition, instead of using ore or concentrate digestion with low $\mathrm{L} / \mathrm{S}$ ratios and high pressures and temperatures, followed by incorporation into an aqueous solution, the proposed direct pressure leaching uses a higher $\mathrm{L} / \mathrm{S}$ ratio and milder conditions for pressure and temperature. The process becomes more flexible, especially for the direct leaching of medium- to high-grade scheelite ores, with an easy industrial implementation.

According to Cho [4], the first researcher that approached the direct leaching of scheelite by sodium carbonate was Maslenitsky (1939). He proposes that the decomposition of scheelite under pressure occurs according to the following reversible chemical reaction:

$\mathrm{CaWO}_{4}$ (solid) $+\mathrm{CO}_{3}{ }^{2^{-}} \rightleftharpoons \mathrm{WO}_{4}{ }^{2^{-}}+\mathrm{CaCO}_{3}$ (solid)

which at $25{ }^{\circ} \mathrm{C}$ has a standard enthalpy of $37.6 \mathrm{~kJ} / \mathrm{mol}$ and a free energy of $56.5 \mathrm{~kJ} / \mathrm{mol}$ [5]. The reversibility of the dissolution reaction was later verified by Queneau and Cooke [6].

Martins and Martins [7] mention that Belikov, Maslenitskii and Queneau assumed a diffusional control for the dissolution rate, while Zelikman and Meerson [8] assumed that the kinetics was chemically controlled. The same authors, in the same article, explained why higher concentrations of calcium carbonate lead to a decrease in tungstate dissolution. According to their research, calcium carbonate precipitates at higher concentrations of $\mathrm{Na}_{2} \mathrm{CO}_{3}$ by interaction with a calcite layer formed at the surface of the mineral grains, and they also suggest that this effect could be minimized by using a sequestering calcium agent, such as $\mathrm{H}_{2} \mathrm{Na}_{2}$ EDTA [7].

More recently, Yang et al. [9] mention that scheelite is normally decomposed during the $\mathrm{Na}_{2} \mathrm{CO}_{3}$ leaching at a temperature in the range $200-230^{\circ} \mathrm{C}$ and that the dosage is normally 2.5-3.5 times the required stoichiometric amount. They also suggest that kinetics is controlled by diffusion and that the use of ultrasound improves the process by reducing or avoiding the formation of a product layer in the solid-liquid interphase.
An important advantage of the use of this leaching process is that compounds of iron, aluminium, titanium, etc. are nearly insoluble in carbonate solutions. Some small amounts of silicates, molybdates, vanadates, phosphates, aluminates and some metal complex carbonates are found in leach solutions in low concentrations. On the other hand, the use of carbonate leaching, unlike acid leaching, requires the use of an integrated, closed-circuit process wherein the leach solutions are recycled. Another possibility is the production of a commercial sub-product, like sodium sulphate, normally used as detergent. Barren leach solutions can also be used to regenerate sodium carbonate. This compound results from the acidification of the leach solutions by sulphuric acid, prior to solvent extraction (SX). Then, the raffinates of SX could be used to produce sodium sulphate thus compensating the high costs in reagents of the leaching operation.

The main objective of this research was to define a flexible hydrometallurgical process that would allow for the direct processing of medium- to high-grade scheelite ores, as well as low-grade scheelite concentrates, in conformity to a generic process framework that involves leaching, solid-liquid separation, elimination of impurities, clarification, solvent extraction and crystallization. The partial recovery of reactants to produce sub-products can also be incorporated in the process. To attain this purpose, sodium carbonate digestion at high temperature and pressure is replaced by direct pressure leaching of the ores at milder pressures and temperatures but with higher sodium carbonate consumptions. Although the post-leaching stages of liquor processing are not included in this article, they were also investigated in detail, leading to the production of crystals of ammonium paratungstate as the final product.

\section{Materials and Methods: Characterization of Samples}

\subsection{Ore Samples}

As in any other hydrometallurgical process, solid-liquid extraction is the pivotal unit operation because it affects irreversibly the metal extraction of the overall process, constraining all the other following unit operations. To characterize and optimize the carbonate leaching operation, samples from a medium-grade scheelite ore (orebody 1) were used as well as samples from two scheelite concentrates: one with a lower grade that was produced by gravity concentration (orebody 1) and another with a high grade that was produced by flotation from a scheelite-chalcopyrite deposit (orebody 2). In orebody 1 , the mineralization occurs in a contact metamorphosed tungsten skarn. A granite/skarn interface is present with mineralization that is next to the granite boundary. Scheelite occurs as fine to coarse disseminations within the skarn horizons. 
Orebody 2 is a skarn-hosted tungsten-copper deposit. The main mineralization is scheelite associated with pyrrhotite, chalcopyrite and major quantities of fluorite.

\subsection{Solid Phase}

The chemical composition of the ore and concentrate samples was evaluated by energy-dispersive $\mathrm{X}$-ray spectroscopy using equipment X-MET 7500 from Oxford Instruments. In order to verify the consistency of the analysis, samples with known grades (measured in a wavelength dispersive X-ray analyzer) were re-analyzed in the X-MET analyzer. The fitting between both assessments was excellent not only for tungsten but also for all other elements analyzed. For this reason, this equipment was used for the analysis of the solid samples using the specific calibration curve, obtained specifically for the assessment of tungsten.

The leaching tests used raw samples from orebody 1 , with grades of $0.45 \%, 0.97 \%$ and $1.24 \%$ in $\mathrm{W}$, concentrates from orebody 1 with an average grade of $19.2 \%$ in W and concentrates from orebody 2 with an average grade of $60.5 \%$ in W. The reason for the tests with a high-grade concentrate from a completely different orebody relies on the fact that it was considered relevant to assess the robustness of the hydrometallurgical process for the treatment of concentrates, especially from different sources.

The grain size distribution for all the samples (Fig. 1) was obtained by laser diffraction, using a Malvern 2000 Particle Size Analyzer with the sample dispersion unit Hydro 2000G. The samples were dispersed in water at $250 \mathrm{rpm}$, and five replicate measurements were performed.

For ore samples (orebody 1), some typical parameters of the mean grain size distribution are the following: $d(0.1)$, $5.3 \mu \mathrm{m} ; d(0.5), 82.5 \mu \mathrm{m}$; and $d(0.9), 295.0 \mu \mathrm{m}$. The volume percentage of particles with grain size below $74 \mu \mathrm{m}(200$ mesh Tyler) was $47.4 \%$. Figure 1 shows the average grain size distribution.

This distribution of the mineralization by different grain size classes for ore samples from orebody 1 was also

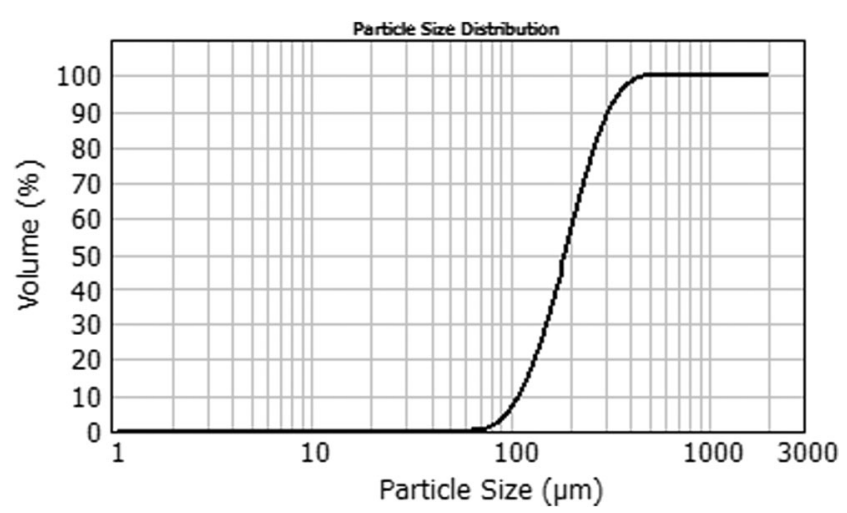

Fig. 1 Grain size distribution of ground W ore evaluated. Figure 2 illustrates the repartition of grades by grain size class using an ore sample with an average grade of $1.24 \%$ in $\mathrm{W}$. The predominant grain size - fraction below $74 \mu \mathrm{m}$ has a higher average grade $-1.59 \% \mathrm{~W}$.

Combining the grain size distribution with the distribution of grades within each class, it was possible to calculate the distribution of $\mathrm{W}$ by grain size. Scheelite mineralization concentrates in the fine fraction below $74 \mu \mathrm{m}$ constitute $77 \%$ of the total $\mathrm{W}$ content.

To evaluate the extension of mineral liberation, a sample of raw and another of processed ore were analyzed by the SEM/ EDS system (FEI Quanta 400FEG ESEM/EDAX Genesis X4M, FEI Company, USA) in high-vacuum mode at 10 or $15 \mathrm{kV}$ to observe size, morphology and distribution. X-ray microanalysis was made in specific fields for elemental characterization. Samples were mounted directly in stubs and stored in a desiccator for a maximum period of $24 \mathrm{~h}$, until SEM/EDS analysis, in order to prevent moisture absorption/ adsorption. At the time of the analysis, stubs were sputtercoated for $60 \mathrm{~s}$ at $15-\mathrm{mA}$ current with a palladium-gold thin film using the SPI Module Sputter Coater equipment.

One example is shown in Fig. 3 where a SEM image of a representative sample of raw ore (scale at the bottom) is shown. Scheelite minerals are easily recognized by its reflectance showing a brighter colour (example-lower particle surrounded by a circle and numbered 1) while the waste rock particles are dull (example - upper particle surrounded by a circle and numbered 2). Several other scheelite particles that have been completely liberated are also visible in the image.

Two selected particles highlighted as numbers 1 and 2 were submitted to X-ray microanalyses. The non-mineralized particle (2) produced the left spectrum, while the mineralized particle (1) was responsible for the right spectrum, both in Fig. 4.

The mineralized particle showed high contents in $\mathrm{W}$ and $\mathrm{Ca}$, confirming that the particle is almost pure scheelite. The non-mineralized particle showed that $\mathrm{Fe}, \mathrm{Si}, \mathrm{Al}, \mathrm{Mg}, \mathrm{Na}$ and $\mathrm{Ca}$ are the prevailing elements, while tungsten was not detected.

\subsection{Liquid Phase}

Tungsten concentrations in the liquid phase were initially determined by flame atomic absorption spectrometry (GBC 932 plus), using a nitrous oxide/acetylene flame at $255.1 \mathrm{~nm}$, slit of $0.2 \mathrm{~nm}$ and a current of $5 \mathrm{~mA}$. The detection limit was $50 \mathrm{mg} / \mathrm{l}$. Calibration lines (coefficient of determination $R^{2}>$ $0.995)$ were obtained in the range $50-1000 \mathrm{mg} / \mathrm{l}$. Whenever necessary, dilutions were made with distilled water in order to obtain tungsten concentrations that were within the linear range.

Later, the chemical analysis of tungsten was performed in a new Atomic Absorption Spectrometer ZEEnit ${ }^{\circledR}$ 700P BU, 
Fig. 2 Distribution of $\mathrm{W}$ grades by grain size

\section{Distribution of grades by grain size}

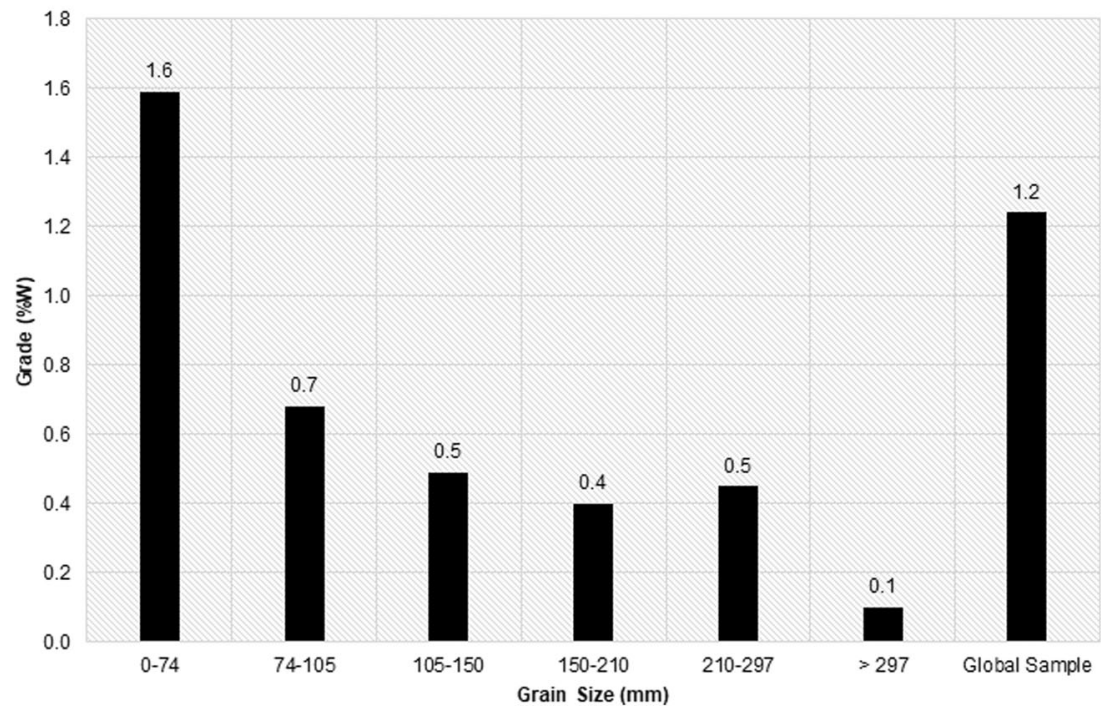

manufactured by Analytik Jena. Wavelength of the hollow cathode lamp was $255.1 \mathrm{~nm}$ with background correction with a deuterium lamp (current of $8 \mathrm{~mA}$, slit of $0.2 \mathrm{~nm}$, burner height of $6 \mathrm{~mm}$ and flow rate of $\mathrm{C}_{2} \mathrm{H}_{2} /$ air and $\mathrm{C}_{2} \mathrm{H}_{2} / \mathrm{N}_{2} \mathrm{O}$ of $80 \mathrm{l} / \mathrm{h}$ and $230 \mathrm{l} / \mathrm{h}$, respectively). Calibration curves were performed before each sample analysis, with analytical standard solutions, with concentrations from 150 to $1200 \mathrm{mg} \mathrm{W} / \mathrm{l}$. The quality control criterion defined for analysis acceptance was a correlation factor higher than 0.995 and a relative standard deviation lower than $5 \%$ between each replicate analysis, for both standards and samples, performed in triplicate. All of the chemicals were analytical grade or higher and used as received.

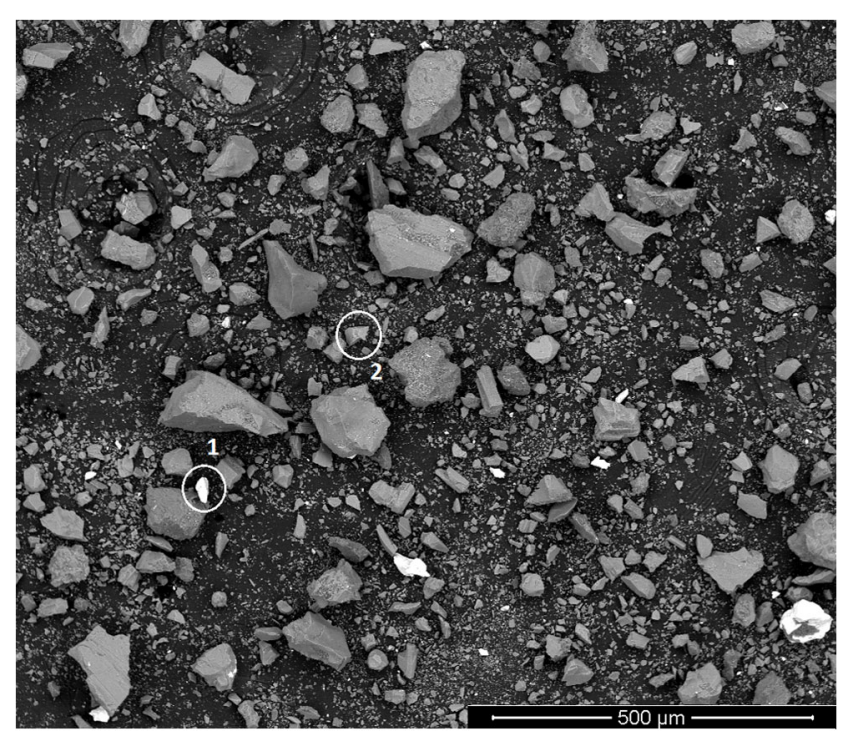

Fig. 3 SEM image of the ground raw ore

\subsection{Pressure Leaching}

Pressure leaching tests were performed in a Parr Reactor (Model 4523-T-TI2-M-230-VS-1000-4848-TDM-CE) in a 1-1 capacity titanium vessel, with maximum stirring at $1815 \mathrm{rpm}$ and with pressure and temperature of $53 \mathrm{bar}$ and $350{ }^{\circ} \mathrm{C}$, respectively. The reactor is equipped with nitrogen (99.999\%) and oxygen (99.995\%) with independent feeding capabilities. Nitrogen regulates pressure and creates an inert atmosphere while oxygen can be added as a reagent if necessary.

\section{Results and Discussion}

\subsection{System Variables}

One of the main research objectives was to study the direct pressure leaching of scheelite ores by sodium carbonate with $\mathrm{L} / \mathrm{S}$ ratios higher or equal to 1 , thus allowing an easy hydraulic transport of the leach pulps. Simultaneously, it was intended to use more moderate operating conditions than those referred in the literature: temperatures between 110 and $180^{\circ} \mathrm{C}$ instead of values between 180 and $250{ }^{\circ} \mathrm{C}$ and pressures in the range 6 13 bar instead of $15-20$ bar.

Twenty-four tests were performed using samples from orebody 1 . The following parameters were considered: grain size, $\mathrm{L} / \mathrm{S}$ ratio, temperature, pressure, residence time, stirring speed, concentration and quantity of the reagent. The following experimental conditions were considered:

- $\quad$ Grain size $(d(0.9) \mu \mathrm{m})-295.02$ and 22.063

- Ore grade $(\mathrm{kg} \mathrm{W} / \mathrm{t}$ of ore) - 4.5, 9.7 and 12.4 

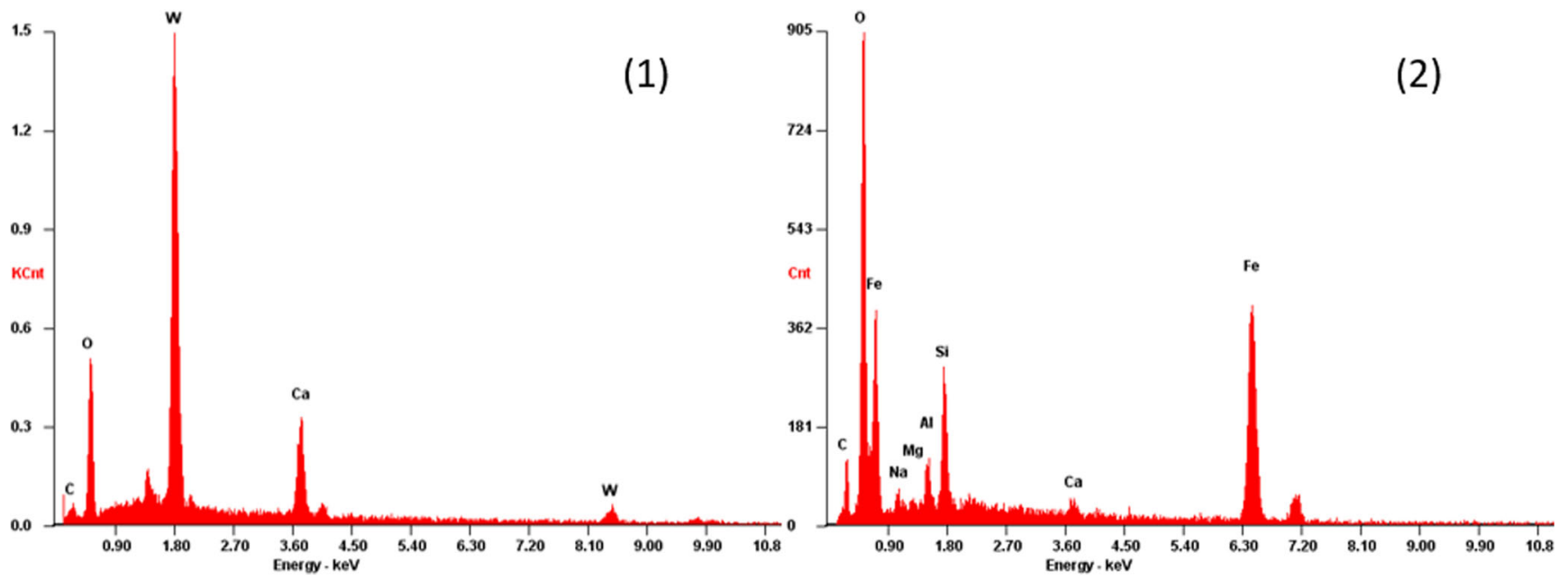

Fig. 4 X-ray spectra of ore particles: mineralized (1) and non-mineralized (2)

- $\quad$ Liquid/solid ratio-1 and 1.2

- Temperatures $\left({ }^{\circ} \mathrm{C}\right) \_90,110,150,160$ and 180

- Pressure (bar) -6, 9.5 and 13

- $\quad$ Residence time (h) $-2,4$ and 8

- $\quad$ Stirring speed (rpm) -200 and 400

- Concentration $\mathrm{Na}_{2} \mathrm{CO}_{3}(\mathrm{~g} / \mathrm{l})-25,50$ and 100

- Quantity of the main reagent ( $\mathrm{kg} /$ ton ore $)-25,30,50$ and 100

- Molar ratio $\mathrm{Na}_{2} \mathrm{CO}_{3} / \mathrm{CaWO}_{4}-3.5,4.2,7$ and 14

As the leaching of scheelite in a sodium carbonate solution occurs according to reaction (1), the equilibrium constant is equal to the molar ratio (or its inverse). Martins [10] deduced the values for the equilibrium constant at different temperatures from thermodynamic data and compared them with the experimental values obtained by Perlov [11] (1.02 vs. 1.21 at $175^{\circ} \mathrm{C}, 1.29$ vs. 1.45 at $200{ }^{\circ} \mathrm{C}, 1.60$ vs. 1.56 at $225^{\circ} \mathrm{C}, 1.95$ vs. 1.85 at $250^{\circ} \mathrm{C}$ ). However, the industrial specific consumptions of carbonate are much higher than expected considering the values of the equilibrium constant, due to the formation of precipitates that consume reactant and impose a diffusional control of the leaching reaction. In agreement with this analysis, Shen et al. [12] also use a thermodynamic approach to prove that $\mathrm{CaWO}_{4}$ is easier leached in $\mathrm{Na}_{2} \mathrm{CO}_{3}$ solution than in $\mathrm{NaOH}$.

For comparison, a blank test at atmospheric pressure and relatively low temperature was also performed. The operating conditions for this test were the following: liquid/solid ratio, 1 ; temperature, $90^{\circ} \mathrm{C}$; pressure, 1 bar; residence time, $2 \mathrm{~h}$; stirring speed, $400 \mathrm{rpm}$; concentration $\mathrm{Na}_{2} \mathrm{CO}_{3}, 100 \mathrm{~g} / 1$ (or $0.94 \mathrm{~mol} / \mathrm{l})$; quantity of the main reagent, $100 \mathrm{~kg} / \mathrm{t}$ ore; and molar ratio $\mathrm{Na}_{2} \mathrm{CO}_{3} / \mathrm{CaWO}_{4}, 14$. Based on the analysis of the solid phases, the extraction was $29 \%$.

\subsection{Leaching of Medium-Grade Scheelite Ore}

As a preliminary interpretation tool, the linear correlation between tungsten extraction and each one of the operating
Fig. 5 Effect of temperature on extraction

\section{Effect of Temperature}

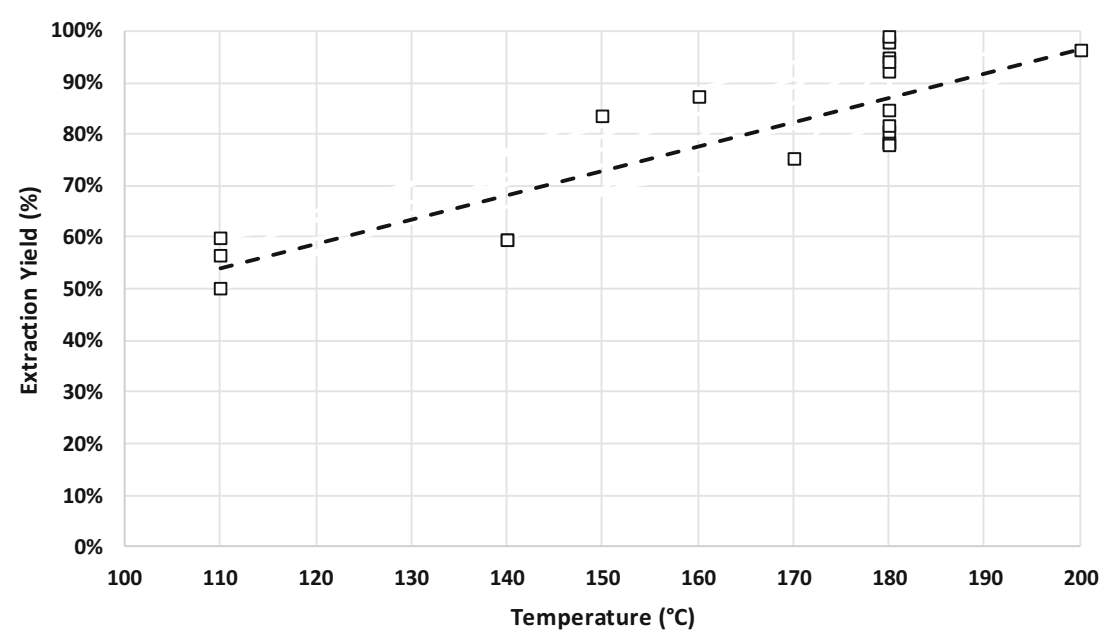


Fig. 6 Effect of pressure on extraction

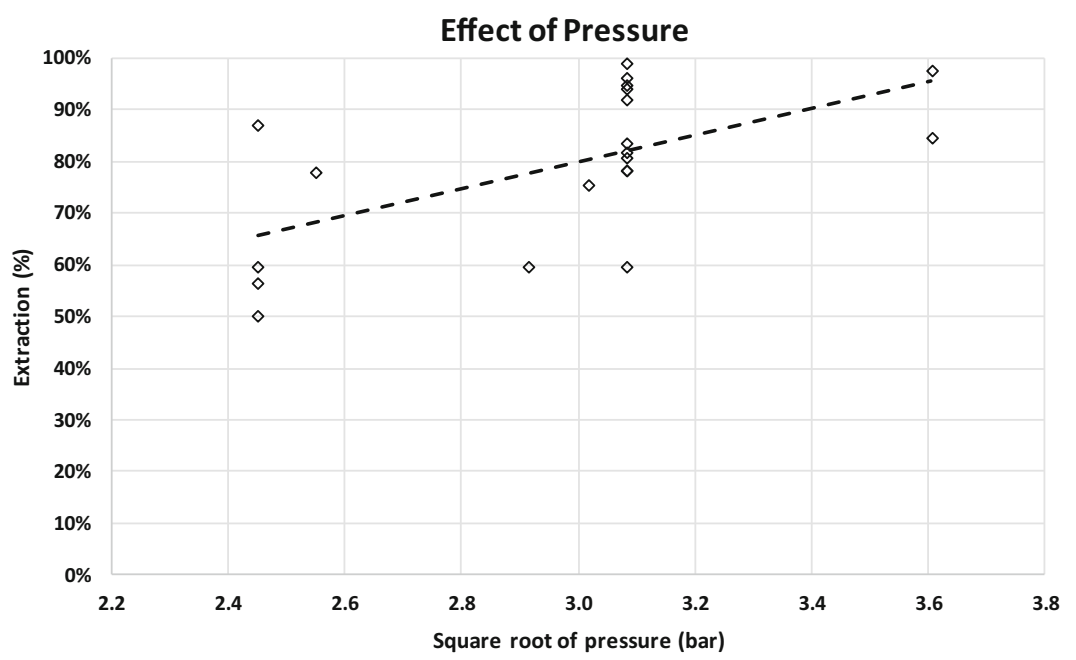

variables was determined for all the samples from orebody 1 . At a confidence level of $99 \%$, the correlation coefficient was acceptable for three variables, temperature, pressure and concentration, in descending order of importance. The other variables (L/S ratio, stirring speed, residence time, ore grade, quantity of reagent and molar ratio) were not significant. One should notice that the ore grades did not differ substantially once they had values between 0.45 and $1.24 \%$ in W. This explains why the molar ratio was not a significant variable.

\subsubsection{Effect of Temperature}

The effect of temperature on the extraction was considered linear. To test this simplified model, all the results from pressure leaching experiments with samples from orebody 1 were taken into account. Fitting was expressed by using both the least squares method (original fit) and a robust fit that excludes as outliers the points at an arbitrary distance greater than 1.5 standard deviations from the baseline model and re-fits the data with the outliers excluded. The robust fit did not improve the regression, which means that no evident outliers existed in the data.

The effect of increased temperature on extraction is evident (Fig. 5), despite the relatively high vertical dispersion of the recoveries for the same temperature, which highlights that recovery also depends on other variables. The correlation coefficient for the least squares fit is 0.854 .

\subsubsection{Effect of Pressure}

In pressure leaching, the recovery is normally affected by the square root of the pressure. Adopting this principle, we assessed the relationship between the leaching recovery and the square root of pressure by a least squares fit (Fig. 6). The
Fig. 7 Fit of the multilinear regression model to the experimental values obtained

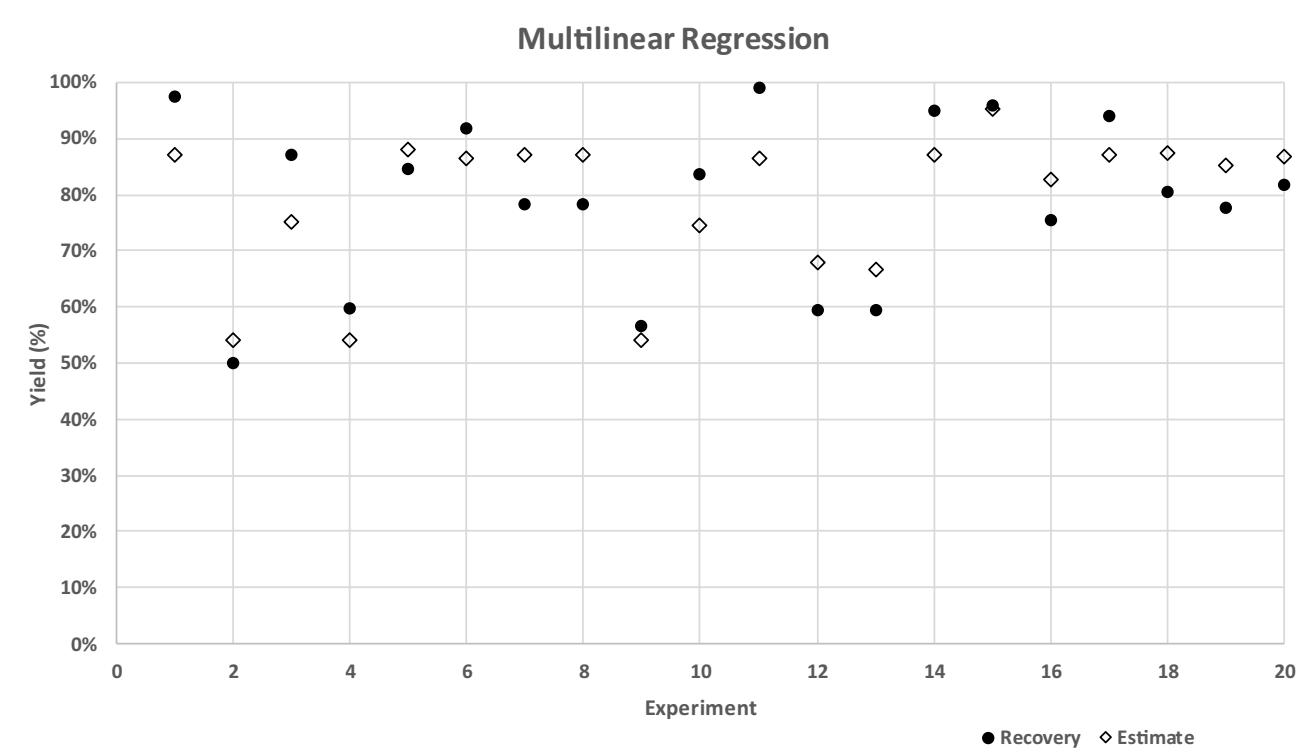


Table 1 Characterization of the leaching solutions

\begin{tabular}{lllll}
\hline & Minimum & Maximum & Average & Standard deviation \\
\hline Concentration (g W/l) & 3.5 & 21.3 & 8.6 & 5.0 \\
$\mathrm{pH}$ & 10.4 & 11.0 & 10.7 & 0.2 \\
Oxidation/reduction potential (mV) & 202.8 & 262.2 & 221.5 & 19.5 \\
1st filtrate concentration (g W/1) & 0.5 & 2.5 & 1.4 & 0.7 \\
Global extraction, liquid phase (\%) & 29 & 100 & 70 & 20 \\
\hline
\end{tabular}

correlation coefficient is 0.6 that is also acceptable for a $99 \%$ confidence level.

The increase in extraction with pressure is evident, but it is noticeable that maximum recoveries co-exist within a wide range of variation in pressure (horizontal dispersion), which emphasizes that it is the combined effect of pressure and temperature that maximizes the yield.

\subsubsection{Effect of Other Operating Conditions}

The $\mathrm{L} / \mathrm{S}$ ratios tested, 1 and 1.2, did not affect the extraction. As a lower ratio corresponds to higher concentrations in the liquid phase, the first ratio (1) was selected as the most convenient. Nevertheless, this parameter is constrained by the grade of the feed, especially for high-grade concentrates, due to the solubility of $\mathrm{Na}_{2} \mathrm{CO}_{3}$ in aqueous solutions, imposing the necessity of higher ratios.

The leaching pressure reactor used does not allow collecting intermediate samples to study the kinetics. Nevertheless, the leaching reaction in the conditions tested is very fast, with a maximum extraction being obtained after $2 \mathrm{~h}$. However, residence times up to $6 \mathrm{~h}$ were also tested.

Stirring speeds from 200 to $500 \mathrm{rpm}$ were evaluated. Similarly, this parameter did not affect the extraction. Due to the relative high viscosity of the pulp (weight solid percentage of $50 \%$ ), a speed of $400 \mathrm{rpm}$ was considered more appropriate.

The molar ratio $\mathrm{Na}_{2} \mathrm{CO}_{3} / \mathrm{CaWO}_{4}$ used in the tests varied from 2.2 to 14 , which corresponded to a quantity of $\mathrm{Na}_{2} \mathrm{CO}_{3}$ of 25 up to $100 \mathrm{~kg} / \mathrm{t}$. This parameter did not significantly affect the leaching yield because the range of ore grades tested was narrow. For industrial scaling and design, the experimental results showed that a ratio between 3.5 and 5 is sufficient.

The concentrations of $\mathrm{Na}_{2} \mathrm{CO}_{3}$ used in the tests ranged from 25 to $124 \mathrm{~g} / 1$ or equivalently from 0.19 to $1.17 \mathrm{~mol} / \mathrm{l}$. This parameter exhibited the third highest correlation with the extraction yield. It should be noted that the coupling of the concentration with the molar ratio determines the specific quantity of the reagent used (mass of $\mathrm{Na}_{2} \mathrm{CO}_{3}$ per mass of ore).

Two of the tests were performed using ultrafine ground ore. The behaviour was similar to the described above, which reveals that scheelite was already liberated and that extra grinding was not necessary.

\subsubsection{Combined Effect of Pressure, Temperature and Concentration-Multilinear Regression Model}

A multilinear regression model was employed to estimate the extraction from the following independent system variables: temperature, square root of pressure and carbonate concentration. The equation of the regression model is as follows:

$\eta=0.0218+0.0042 T+0.0314 \sqrt{P}-0.0202 C$

where $\eta$ represents the extraction in a dimensional form, $T$ is the temperature in ${ }^{\circ} \mathrm{C}, P$ is the pressure in bar and $C$ is the carbonate concentration in mole per litre. The multilinear correlation coefficient is 0.86 and the standard error of the estimate is 0.078 . This correlation coefficient for three independent variables is acceptable at a $99 \%$ confidence level. Figure 7 represents the value obtained for the extraction and the correspondent estimated value calculated for each experiment using the multilinear regression model.

The residuals of the fit have an average of 0.0057 , a value near zero. The distribution of the residuals was tested against the normal law at a confidence level of 0.05 using the Kolmogorov-Smirnov test. The hypothesis of normality was acceptable, and therefore, we may consider the residuals a pseudo-random variable. In fact, they depend to a nonquantifiable extent on the values of the other operating conditions, but also on the errors associated with the experimental procedures. They can be considered a random component,
Table 2 Concentrations of impurities in the leaching solutions

\begin{tabular}{llllll}
\hline Sample test no. 1 & $\mathrm{~W}$ & $\mathrm{PO}_{4}{ }^{3-}(\mathrm{mg} / \mathrm{l})$ & $\mathrm{SiO}_{2}(\mathrm{mg} / \mathrm{l})$ & $\mathrm{Mo}(\mathrm{mg} / \mathrm{l})$ & $\mathrm{Fe}$ total $(\mathrm{mg} / \mathrm{l})$ \\
& $1.80 \%$ & $<0.05$ & 630 & 1.5 & $<0.03$ \\
Sample test no. 10 & $\mathrm{~W}$ & $\mathrm{PO}_{4}{ }^{3-}(\mathrm{mg} / \mathrm{l})$ & $\mathrm{SiO}_{2}(\mathrm{mg} / \mathrm{l})$ & $\mathrm{Mo}(\mathrm{mg} / \mathrm{l})$ & $\mathrm{Fe} \mathrm{total}(\mathrm{mg} / \mathrm{l})$ \\
& $0.54 \%$ & $<0.05$ & 11 & 1.5 & $<0.03$ \\
\hline
\end{tabular}




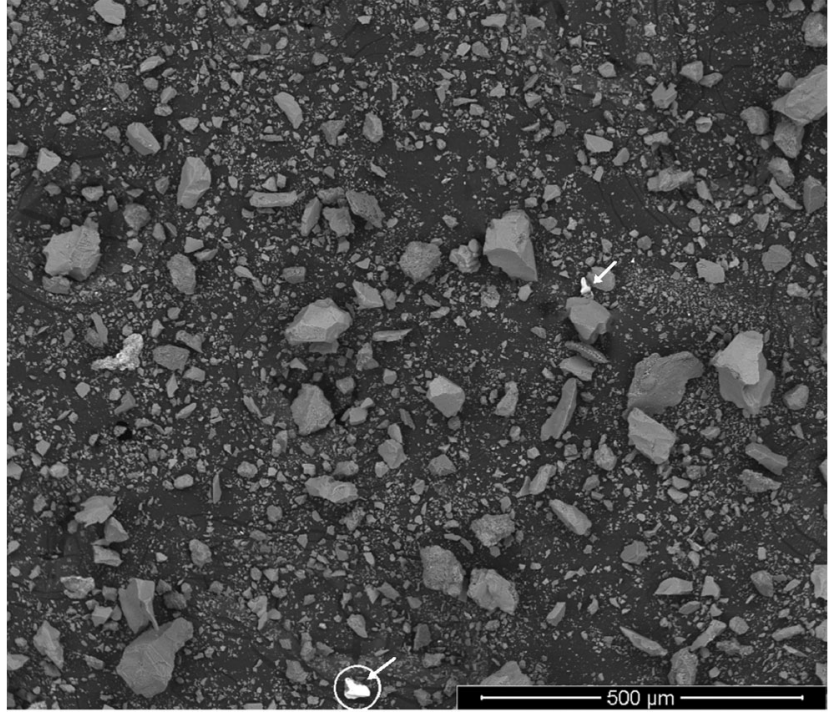

Fig. 8 SEM of the residue

which sums to the deterministic component estimated by the multilinear regression model.

\subsubsection{Characterization of the Liquid Phase}

The following analytical parameters were determined for the liquid phases:

- Concentration of $\mathrm{W}$ in the leachate

$-\mathrm{pH}$

- Oxidation/reduction potential $(\mathrm{mV})$

Fig. 9 X-ray spectrum of a scheelite particle in the residue
- Concentration of W in the washing solutions of the filtrate cakes

As expected, the leaching solutions were very alkaline with an average $\mathrm{pH}$ of 10.7 and a reducing redox potential varying between 120 and $240 \mathrm{mV}$. Concentrations of $\mathrm{W}$ ranged from 3.5 to $11.4 \mathrm{~g} / \mathrm{l}$. A summary of the experimental values obtained (minimum, maximum, average and standard deviation) is shown in Table 1.

Some elements, such as As, Mo, $\mathrm{P}, \mathrm{SiO}_{2}$ and $\mathrm{Fe}$, may have an interfering action in the subsequent steps of the overall process. To evaluate the presence of these elements, two leaching liquors, obtained in different leaching tests, were analyzed and the results are presented in Table 2.

\subsubsection{SEM of the Leaching Residue}

Several samples of leaching residues were viewed by SEM. Figure 8 is representative of the images obtained, and it is clearly seen that, in the observed field, only two mineralized particles, highlighted with white arrows, are present.

The scheelite particle outlined in a white circle was submitted to X-ray microanalysis. The obtained spectrum, shown in Fig. 9, confirms that the particle is constituted by scheelite that was not leached.

\subsection{Leaching of Scheelite Concentrates}

Two tests were performed using scheelite concentrates: one with a low grade from orebody 1 , with a grade of $19.2 \%$ in W,

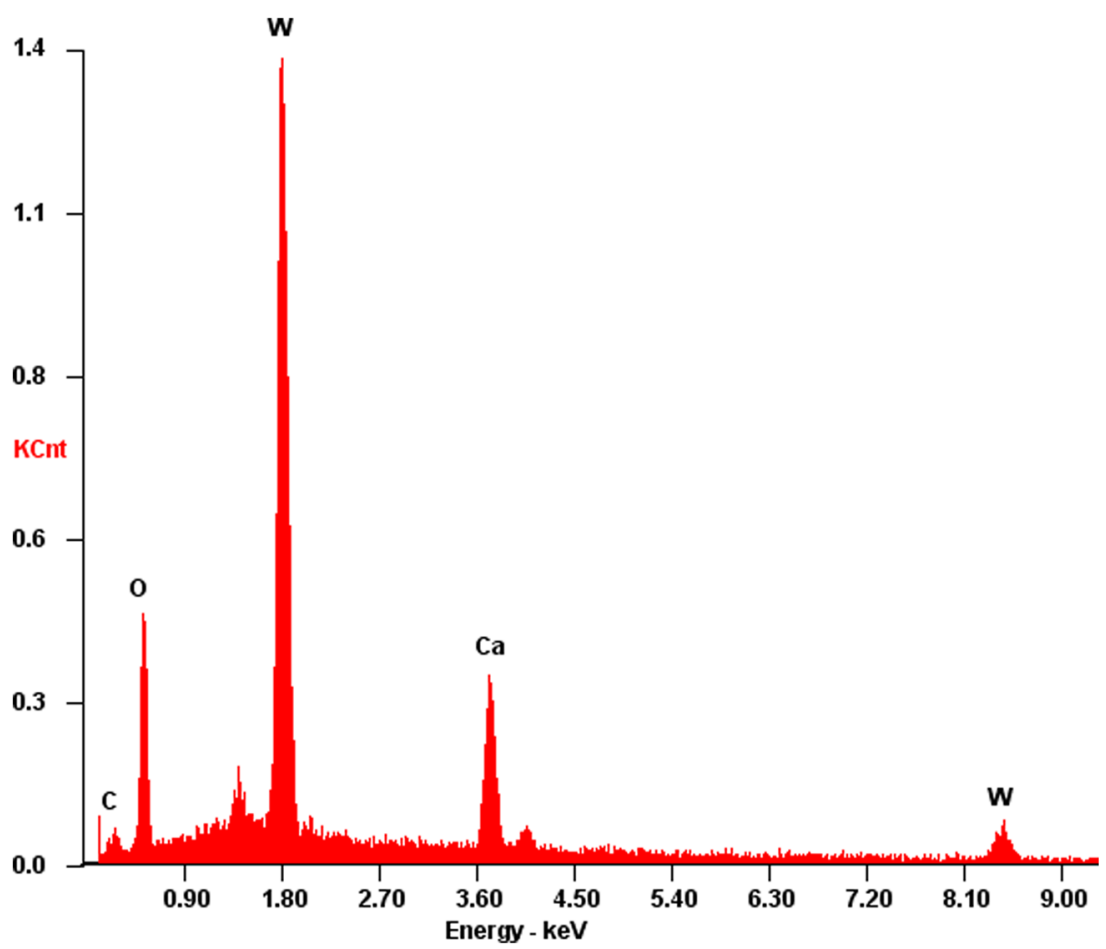


produced by gravity separation using a shaking table and the other from orebody 2 , produced by flotation, with a high grade of $60.45 \%$. The flotation concentrate had the following grain size distribution: $d(0.1)=109.504 \mu \mathrm{m}, d(0.5)=188.579 \mu \mathrm{m}$ and $d(0.9)=311.053 \mu \mathrm{m}$.

In relation to the previous tests, it was necessary to drastically change the L/S ratio because of the solubility values of $\mathrm{Na}_{2} \mathrm{CO}_{3}$ in water. The maximum solubility for the anhydrous compound occurs at $34{ }^{\circ} \mathrm{C}$ and is $486.9 \mathrm{~g} / \mathrm{L}$. For the low-grade concentrate, a $\mathrm{L} / \mathrm{S}$ ratio of 4 was used with a molar ratio of 6.4 , while for the high-grade concentrate, a $\mathrm{L} / \mathrm{S}$ ratio of 10 with a molar ratio of 5 was used. Values for the solubility of $\mathrm{Na}_{2} \mathrm{CO}_{3}$ in water can be found in Seidell and Linke [13] and Lide [14].

The other operating conditions remained the same: temperature, $180^{\circ} \mathrm{C}$; pressure, $9.5 \mathrm{bar}$; and residence time, $2 \mathrm{~h}$. The recoveries were $82 \%$ in the first case and $88 \%$ in the second case.

\subsection{Flowsheet for Pressure Alkaline Leaching}

The direct pressure alkaline leaching of medium- to highgrade scheelite ores can be implemented using the flowsheet proposed in Fig. 10. Grinding is suggested to be performed in two stages, using a rod mill and a ball mill. The crushed ore feeds the rod mill where a coarse grind occurs. The ground ore together with the material coming from the ball mill is classified by hydrocyclones. The underflow is ground in the ball mill and the overflow is thickened. The underflow of the thickener proceeds to leaching, while the overflow, mainly constituted by water, is recycled to grinding. The objective is to guarantee liberation and simultaneously avoid overgrinding. After grinding, the pulp is stored in a stirred tank. It should be noted that grinding can be accomplished using other possible arrangements that depend mainly on scheelite liberation.

Dissolution of tungsten can be performed in autoclaves at a pressure of 9.5 bar and a temperature of $180{ }^{\circ} \mathrm{C}$, with a

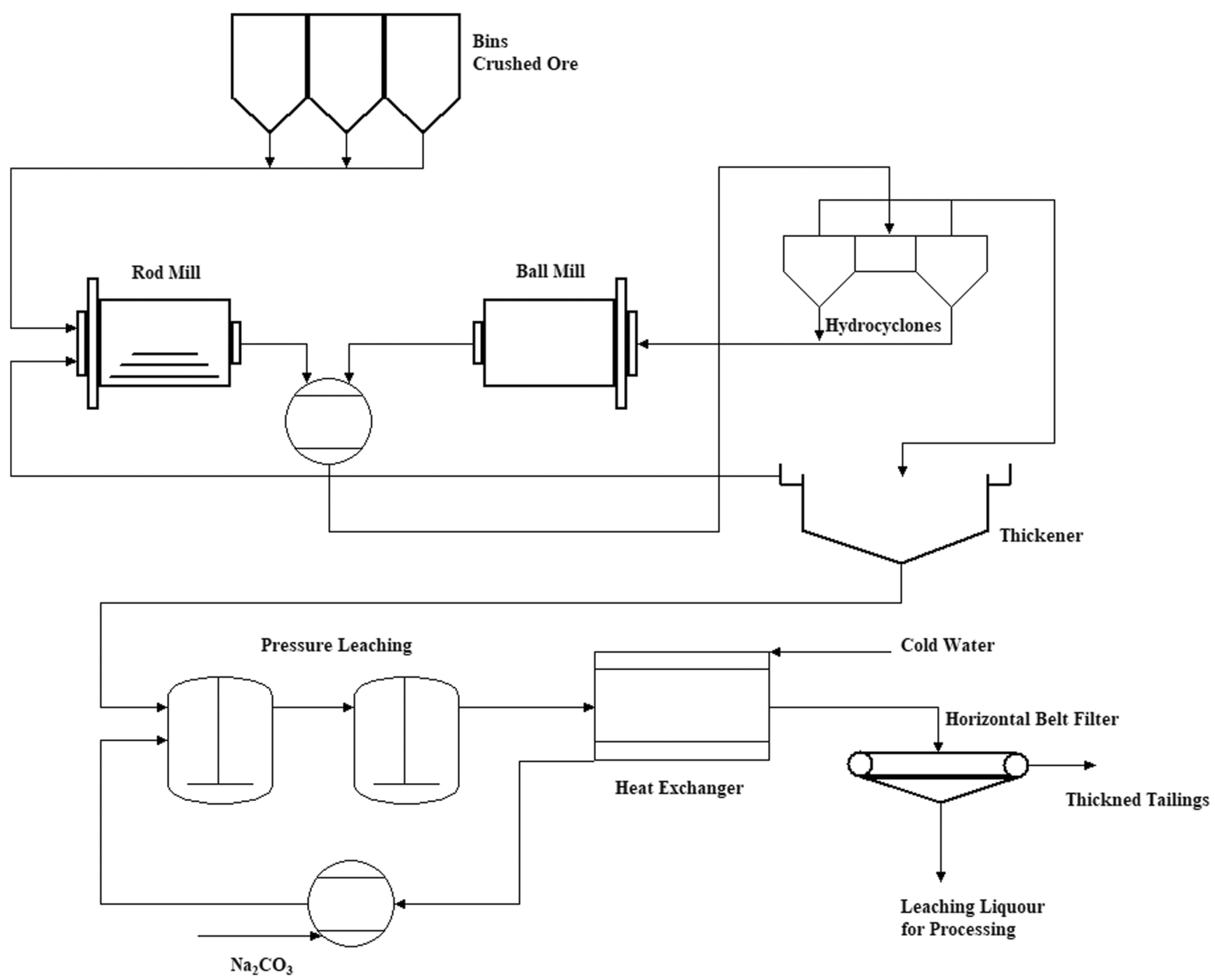

Fig. 10 Flowsheet for direct soda ash pressure leaching of scheelite ores 
residence time of $2 \mathrm{~h}$. After leaching, the pulp is cooled by fresh cold water in a heat exchanger. The warmed water is used to prepare the leaching carbonate solution while the pulp proceeds to solid-liquid separation. This last operation can be performed in a horizontal belt filter, to ensure the production of a consistent low moisture cake ready for environmentally safe tailings storage. The filtrate will proceed to further processing for enrichment and purification.

In the case of processing concentrates produced by flotation, grinding operations will not be necessary.

\section{Conclusions}

The sodium carbonate pressure leaching of scheelite ores and/ or concentrates is a flexible process that can be used in two different circumstances: directly with a medium- to highgrade ore, thus avoiding the necessity of a previous treatment by physical methods (gravity or flotation), and/or also with concentrates that were previously enriched by those techniques.

The process proposed uses direct pressure leaching of ores or concentrates. The operatory conditions, temperature and pressure, are much milder than those proposed in the literature. In opposition, the consumption of sodium carbonate is higher. The process diagram is simple, flexible and straightforward. The upscaling and design for implementation of a pilot plant is relatively easy.

Operating conditions are flexible and can be adapted to the type of ore guaranteeing a high extraction and an optimization of consumables and energy.

Acknowledgements The authors gratefully acknowledge the support of the CERENA research centre (FEUP section). They thank CEMUPCentro de Materials da Universidade do Porto-for the expert assistance and helpful discussions about SEM measurements.

Funding Information The manuscript has been developed within the R\&D project FAME-Flexible and mobile economic processing technologies - and is co-funded under Horizon 2020 by the European Commission (GA number 641650) within the call SC5-11b-2014: flexible-processing technologies.

\section{Compliance with Ethical Standards}

Conflict of Interest The authors declare that they have no conflict of interest.
Open Access This article is distributed under the terms of the Creative Commons Attribution 4.0 International License (http:// creativecommons.org/licenses/by/4.0/), which permits unrestricted use, distribution, and reproduction in any medium, provided you give appropriate credit to the original author(s) and the source, provide a link to the Creative Commons license, and indicate if changes were made.

\section{References}

1. European Commission (2011) Communication from the Commission to the European Parliament, the Council, the European Economic and Social Committee and the Committee of the Regions Tackling the challenges in commodity markets and on raw materials

2. Dvořáček J, Sousedíková R, Vrátný T, Jureková Z (2017) Global tungsten demand and supply forecast. Arch Min Sci 62(1):3-12. https://doi.org/10.1515/amsc-2017-0001

3. Gau RS (2006) Modern hydrometallurgical production methods for tungsten. JOM:58-59. https://doi.org/10.1007/s11837-006-0082-0

4. Cho EH (1988) Kinetics off sodium carbonate leaching of scheelite. JOM 40:32-34. https://doi.org/10.1007/BF03258147

5. Martins JP (1996) Kinetics of soda ash leaching of low-grade scheelite concentrates. Hydrometallurgy:42-42. https://doi.org/10. 1016/0304-386X(95)00099-3

6. Queneau PB, Cooke SRB (1969) The kinetics of the dissolution of scheelite in alkaline aqueous solutions. Trans AIME 245

7. Martins JP, Martins F (1997) Soda ash leaching of scheelite concentrates: the effect of high concentration of sodium carbonate. Hydrometallurgy 46:46-41. https://doi.org/10.1016/S0304386X(97)00013-3

8. Zelikman AN, Meerson GA, Metallurgiya Redkikh Metallov, Metallurgiya 1973

9. Yang J-h, He L-h, Liu X-h, Ding W-t, Song Y-f, Zhao Z-w (2018) Comparative kinetic analysis of conventional and ultrasoundassisted leaching of scheelite by sodium carbonate. Trans Nonferrous Met Soc China 28:775-782. https://doi.org/10.1016/ S1003-6326(18)64710-7

10. Martins JI (2014) Leaching systems of wolframite and scheelite: a thermodynamic approach. Miner Process Extr Metall Rev 35:2343. https://doi.org/10.1080/08827508.2012.757095

11. Perlov PM (1958) Interaction calcium tungstate with soda solutions in the autoclave process. Obogash Rud 3

12. Shen L, Li X, Taskinen P (2018) Thermodynamics of tungsten ores decomposition process options, Conference Extraction, Ontario. https://doi.org/10.1007/978-3-319-95022-8 206

13. Seidell A, Linke FW (1919) Solubilities of inorganic and organic compounds, 2nd edn. D. Van Nostrand Company, New York

14. Lide DR (2009) CRC handbook of chemistry and physics (90th ed.). CRC Pres, Boca Raton ISBN 978-1-4200-9084-0

Publisher's Note Springer Nature remains neutral with regard to jurisdictional claims in published maps and institutional affiliations. 